Pacific Journal of Mathematics

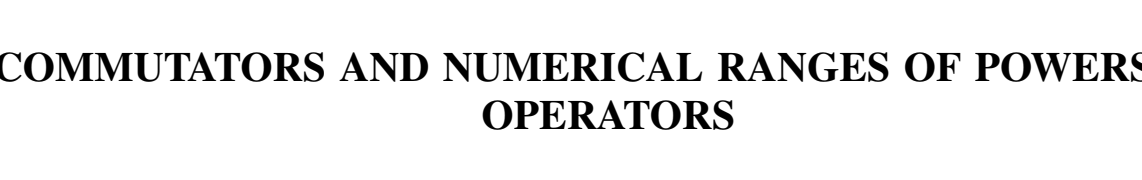




\title{
COMMUTATORS AND NUMERICAL RANGES OF POWERS OF OPERATORS
}

\author{
Elias S. W. SHIU
}

\begin{abstract}
If 0 does not lie in the closure of the numerical range of any positive integral power of a Hilbert space operator $T$, then an odd power of $T$ is normal. If, in addition, $T$ is convexoid, then $T$ itself is normal; in fact, $T$ is the direct sum of at most three rotated positive operators. A version of these results is given in terms of commutators.
\end{abstract}

1. Introduction. In [8] C. R. Johnson proved: For an $m \times m$ complex matrix $A$, if $A^{n}$ is not normal for any positive integer $n$, then there exist a positive integer $n_{0}$ and a nonzero vector $x \in C^{m}$ such that $\left(A^{n_{0}} x, x\right)=0$. Later he and M. Neuman [9] obtained a number theoretic result which strengthens the above theorem. We generalize these theorems to the Hilbert space operator case in this paper.

Let $\mathscr{B}(\mathscr{H})$ denote the set of bounded operators on a Hilbert space $\mathscr{H}$. For $T \in \mathscr{B}(\mathscr{C}), \bar{W}(T)$ denotes the closure of the numerical range of $T$. Our main results are: If $0 \notin \bar{W}\left(T^{n}\right), n=1$, $2,3, \cdots$, then an odd power of $T$ is normal; in fact, $T$ is similiar to the direct sum of at most three rotated positive operators. Moreover, under the above hypothesis, $T$ is normal if and only if $T$ is convexoid.

These results can be applied to the theory of commutators: Let $\mathfrak{S}$ denote a separable infinite dimensional Hilbert space. For $T \in \mathscr{B}(\mathscr{E})$, if $T^{n} \notin\{S X-X S: S, X \in \mathscr{B}(\mathscr{E}), \quad S$ positive $\}, \quad n=1,2$, $3, \cdots$, then there are an odd integer $k$ and a compact operator $K$ such that $T^{k}+K$ is normal; furthermore, $T$ is a compact perturbation of a normal operator if and only if the essential numerical range of $T$ is a polygon (possibly degenerate).

2. Preliminaries. Let $C$ denote the set of complex numbers and $\boldsymbol{R}^{+}$the set of strictly positive numbers. For $\Omega \subset \boldsymbol{C}, \operatorname{Co}(\Omega)$ denotes its convex hull; $\Omega^{n}=\left\{z^{n}: z \in \Omega\right\}, n$ a positive integer. We write $\Omega>r, r$ a real number, if $\Omega$ is a real subset and each number in $\Omega$ is greater than $r$. Let $\alpha, \beta \in C$ and $\varepsilon \in(0,1], \Theta(\alpha, \beta ; \varepsilon)$ denotes the closed elliptical disc with eccentricity $\varepsilon$ and foci at $\alpha$ and $\beta$,

$$
\Theta(\alpha, \beta ; \varepsilon)=\{z \in C:|z-\alpha|+|z-\beta| \leqq|\alpha-\beta| / \varepsilon\} \text {. }
$$


Note that $\Theta(\alpha, \beta ; 1)$ is the line segment joining $\alpha$ and $\beta$.

LEMma 1. Let $\alpha, \beta$ be two distinct nonzero complex numbers. For $\varepsilon \in(0,1]$, if $|\operatorname{Arg}(\alpha / \beta)| \geqq \arccos \left(-\varepsilon^{2}\right)$, then $0 \in \Theta(\alpha, \beta ; \varepsilon)$.

For $T \in \mathscr{B}(\mathscr{H}), \sigma(T)$ denotes the spectrum and $W(T)$ the numerical range of $T, W(T)=\{(T x, x):\|x\|=1\}$. We say $T$ is positive and write $T>0$ if $\bar{W}(T)>0 . \quad T$ is called convexoid if $\operatorname{Co}(\sigma(T))=\bar{W}(T)[6, \mathrm{p} .114]$.

The following result describes the numerical range of a $2 \times 2$ matrix with distinct eigenvalues ([12], [10]).

LemmA 2. If $\alpha \neq \beta$, then $W\left(\left(\begin{array}{ll}\alpha & \gamma \\ 0 & \beta\end{array}\right)\right)=\Theta\left(\alpha, \beta ;\left(1+|\gamma /(\alpha-\beta)|^{2}\right)^{-1 / 2}\right)$.

Let $\mathscr{H} \oplus \mathscr{K}$ denote the direct sum of two Hilbert spaces $\mathscr{H}$ and $\mathscr{K}$; an operator on $\mathscr{H} \oplus \mathscr{K}$ may be expressed as a $2 \times 2$ matrix whose entries are operators. See [6, Chapter 7].

LEMma 3. Let $T \in \mathscr{B}(\mathscr{H} \oplus \mathscr{K}), T=\left(\begin{array}{ll}A & B \\ C & D\end{array}\right)$. Then

$$
W(T)=\cup\left\{W\left(\left(\begin{array}{ll}
(A x, x) & (B y, x) \\
(C x, y) & (D y, y)
\end{array}\right)\right): x \in \mathscr{H}, y \in \mathscr{K},\|x\|=\|y\|=1\right\} .
$$

Let $T \in \mathscr{B}(\mathscr{H})$ with $\sigma(T)=\sigma_{1} \cup \sigma_{2}$, where $\sigma_{1}$ and $\sigma_{2}$ are disjoint, nonempty and closed. Let $E$ be the spectral projection associated with $\sigma_{1}[18, \S 5.7]$; then $E^{2}=E, E T=T E, \sigma\left(\left.T\right|_{E \mathscr{C}}\right)=\sigma_{1}$ and $\sigma\left(\left.T\right|_{(I-E) * C}\right)=\sigma_{2}$. We note that $E$ may not be Hermitian.

Lemma 4 (cf. $[13, \S 0.4]$ ). Let $T$ and $E$ be as above and let $P$ be the orthogonal projection on $E \mathscr{H}$. Then, with respect to the decomposition $E \mathscr{H} \oplus(E \mathscr{H})^{\perp}$, the operator matrix corresponding to $T$ has the form $\left(\begin{array}{cc}T_{1} & T_{1} A-A T_{2} \\ 0 & T_{2}\end{array}\right)$, where $\left(\begin{array}{ll}0 & A \\ 0 & 0\end{array}\right)=E-P$ and

$$
\sigma\left(T_{i}\right)=\sigma_{i}, i=1,2 .
$$

Furthermore, $T_{1} A-A T_{2}=0$ if and only of $A=0$.

The following result is proved in ([14], [15]).

LEMma 5. For $T \in \mathscr{B}(\mathscr{H})$ and $\sigma(T)>\gamma>0$, if $\left\{z \in C:|z| \leqq \gamma^{n}\right\} \not \subset$ $W\left(T^{n}\right)$ for infinitely many positive integers $n$, then $T>0$.

3. Main results. The following generalizes [8, Theorem 1].

TheOREM 1. Let $T \in \mathscr{B}(\mathscr{H})$ with $\sigma(T) \cap \boldsymbol{R}^{+} \neq \varnothing$. Suppose 
$0 \notin \bar{W}\left(T^{n}\right), \quad n=1,2,3, \cdots$, then either (i) there is a positive odd integer $m$ such that $T^{m}>0$ or (ii) there exist a proper closed subspace $\mathscr{H}_{1}$ of $\mathscr{\mathscr { C }}$ and positive operators $T_{1}$ and $T_{2}$ on $\mathscr{H}_{1}$ and $\mathscr{C}_{1}{ }^{\perp}$ respectively such that $T=T_{1} \oplus e^{i \theta} T_{2}, \theta$ being irrational modulo $2 \pi$.

Proof. Since $0 \notin \bar{W}\left(T^{n}\right) \supset \operatorname{Co}\left(\sigma\left(T^{n}\right)\right)=\operatorname{Co}\left(\sigma(T)^{n}\right), \quad n=1,2,3, \cdots$, either (i) there is an odd integer $m$ such that $\sigma(T)^{m} \subset \boldsymbol{R}^{+}$or (ii) $\sigma(T) \subset \boldsymbol{R}^{+} \cup e^{i \theta} \cdot \boldsymbol{R}^{+}, \theta$ being irrational modulo $2 \pi$.

In case (i), $\sigma\left(T^{m}\right)>0$. Thus we have $T^{m}>0$ by Lemma 5 .

In case (ii) we apply Lemma 4 with $\sigma_{1}=\sigma(T) \cap \boldsymbol{R}^{+}$. Then

$$
T=\left(\begin{array}{cc}
T_{1} & T_{1} A-e^{i \theta} A T_{2} \\
0 & e^{i \theta} T_{2}
\end{array}\right)
$$

where $\sigma\left(T_{1}\right)>0$ and $\sigma\left(T_{2}\right)>0$. Since $T^{n}=\left(\begin{array}{cc}T_{1}^{n} & T_{1}^{n} A-e^{i n \theta} A T_{2}^{n} \\ 0 & e^{i n \theta} T_{2}^{n}\end{array}\right)$, $W\left(T^{n}\right) \supset W\left(T_{1}^{n}\right)$ and $W\left(T^{n}\right) \supset W\left(e^{2 n \theta} T_{1}^{n}\right)$, we have $T_{1}>0$ and $T_{2}>0$ by Lemma 5.

To show that $T=T_{1} \oplus e^{i \theta} T_{2}$, we have to show $A=0$. Assume $A \neq 0$. For a positive integer $n$ and $y \in(E \mathscr{C})^{\perp}$, with $\|y\|=1$ and $A y \neq 0$, let $\Theta[n, y]$ denote the numerical range of the $2 \times 2$ matrix

$$
\left(\begin{array}{cc}
\left(T_{1}^{n} A y, A y\right) /\|A y\|^{2} & \left(\left(T_{1}^{n} A y, A y\right)-e^{i n \theta}\left(A T_{2}^{n} y, A y\right)\right) /\|A y\| \\
0 & e^{i n \theta}\left(T_{2}^{n} y, y\right)
\end{array}\right) .
$$

By Lemma 3, $\Theta[n, y] \subset W\left(T^{n}\right)$. By Lemma $2, \Theta[n, y]=\Theta(\alpha, \beta ; \varepsilon[n, y])$, where $\alpha \in \boldsymbol{R}^{+}, \beta \in e^{i n \theta} \boldsymbol{R}^{+}$and

$$
\varepsilon[n, y]=\left(1+\left|\frac{\left(\left(T_{1}^{n} A y, A y\right)-e^{i n \theta}\left(A T_{2}^{n} y, A y\right)\right) /\|A y\|}{\left(T_{1}^{n} A y, A y\right) /\|A y\|^{2}-e^{i n \theta}\left(T_{2}^{n} y, y\right)}\right|^{2}\right)^{-1 / 2} .
$$

Let $y_{m}, m=1,2,3, \cdots$ be a sequence in $(E \mathscr{C})^{\perp}$ such that $\left\|y_{m}\right\|=1$ and $\lim _{m \rightarrow \infty}\left\|A y_{m}\right\|=\|A\|$. For each $n$,

$$
\begin{aligned}
& \frac{\left(\left(T_{1}^{n} A y_{m}, A y_{m}\right)-e^{i n \theta}\left(T_{2}^{n} y_{m}, A^{*} A y_{m}\right)\right) /\left\|A y_{m}\right\|^{2}}{\left(T_{1}^{n} A y_{m}, A y_{m}\right) /\left\|A y_{m}\right\|^{2}-e^{i n \theta}\left(T_{2}^{n} y_{m}, y_{m}\right)} \\
& \quad=1+\frac{e^{i n \theta}\left(T_{2}^{n} y_{m},\left(\left\|A y_{m}\right\|^{2}-A^{*} A\right) y_{m}\right)}{\left(T_{1}^{n} A y_{m} A, y_{m}\right) /\left\|A y_{m}\right\|^{2}-e^{i n \theta}\left(T_{2}^{n} y_{m}, y_{m}\right)} \longrightarrow 1 \text { as } m \longrightarrow \infty
\end{aligned}
$$

Hence $\lim _{m \rightarrow \infty} \varepsilon\left[n, y_{m}\right]=\left(1+\|A\|^{2}\right)^{-1 / 2}$. Thus for each integer $n$, there is an integer $m(n)$ such that

$$
\varepsilon\left[n, y_{m(n)}\right] \leqq\left(1+\|A\|^{2} / 2\right)^{-1 / 2}<1 .
$$

Since $\theta$ is irrational modulo $2 \pi$, we can pick a positive integer $N$ for which $\left|\operatorname{Arg} e^{i N \theta}\right| \geqq \arccos \left(-/\left(1+\|A\|^{2} / 2\right)\right)$. Then $0 \in \Theta\left[N, y_{m(N)}\right]$ by Lemma 1. However, $0 \notin W\left(T^{N}\right)$ by hypothesis; $A=0$ and $T=T_{1} \oplus e^{i \theta} T_{2}$. 
We note that if $\mathscr{H}$ is finite dimensional, the proof of case (ii) can be greatly simplified: Let $\alpha, \beta \in C$ and $\alpha^{n} \neq \beta^{n}, n=1,2,3, \cdots$, then $W\left(\left(\begin{array}{cc}\alpha & \beta \\ 0 & \alpha\end{array}\right)^{n}\right)=\Theta\left(\alpha^{n}, \beta^{n} ;\left(1+|\gamma /(\alpha-\beta)|^{2}\right)^{-1 / 2}\right)$ by Lemma 2 .

For $\mathscr{C} \subset C \backslash\{0\}$, let $\#$ Arg $\mathscr{C}$ denote the cardinality of the set $\{\lambda /|\lambda|: \lambda \in \mathscr{C}\}$. The result in [9] may be stated as follows: Let $\mathscr{C}$ be a compact set of nonzero complex numbers such that $\mathscr{C} \cap \boldsymbol{R}^{+} \neq \varnothing$. If $0 \notin \mathrm{Co}\left(\mathscr{C}^{n}\right), n=1,2,3 \cdots$, and if $\# \operatorname{Arg} \mathscr{C} \geqq 3$, then $\# \operatorname{Arg} \mathscr{C}=3$ and $\mathscr{C}^{7} \subset \boldsymbol{R}^{+}$.

Theorem 1'. Let $T \in \mathscr{B}(\mathscr{H})$ with $\sigma(T) \cap \boldsymbol{R}^{+} \neq \varnothing$. Suppose $0 \notin$ $\bar{W}\left(T^{n}\right), n=1,2,3,, \cdots$. We have the following cases:

(i) $\# \operatorname{Arg} \sigma(T)=1$ then $T>0$.

(ii) \#Arg $\sigma(T) \geqq 3$, then \#Arg $\sigma(T)=3$ and $T^{7}>0$.

(iii) \#Arg $\sigma(T)=2$, then either there is a positive odd integer $m$ such that $T^{m}>0$ or there exist a closed subspace $\mathscr{H}_{1}$ of $\mathscr{H}$ and positive operators $T_{1}$ and $T_{2}$ on $\mathscr{H}_{1}$ and $\mathscr{H}_{1}{ }^{\perp}$ respectively such that $T=T_{1} \oplus e^{i \theta} T_{2}, \theta$ being irrational modulo $2 \pi$.

Theorem 2. Let $T \notin \mathscr{B}(\mathscr{H})$. Suppose $0 \notin \bar{W}\left(T^{n}\right), n=1,2,3, \cdots$. Then $T$ is normal if $T$ is convexoid.

Proof. By Theorem 1', \#Arg $\sigma(T) \leqq 3$. First, we consider the case $\# \operatorname{Arg} \sigma(T)=2$, i.e., there are two real numbers $\theta_{1}$ and $\theta_{2}$ such that $\sigma(T) \subset e^{i \theta_{1}} \cdot \boldsymbol{R}^{+} \cup e^{i \theta_{2}} \cdot \boldsymbol{R}^{+}$. Let $E$ be the spectral projection associated with $\sigma(T) \cap e^{i \theta_{1}} \cdot \boldsymbol{R}^{+}$. With respect to $E \mathscr{H} \oplus(E \mathscr{H})^{\perp}$, put $E=\left(\begin{array}{cc}I & A \\ 0 & 0\end{array}\right)$, then $T=\left(\begin{array}{cc}e^{i \theta_{1}} T_{1} & e^{i \theta_{1}} T_{1} A-A e^{i \theta_{2}} T_{1} \\ 0 & e^{i \theta_{2}} T_{2}\end{array}\right)$, where $T_{1}>0$ and $T_{2}>0$. Assume $A \neq 0$; thus there is a two-dimensional compression of $T$ whose numerical range consists of an elliptical disc with foci on each of the two half-rays $e^{i \theta_{j}} \cdot \boldsymbol{R}^{+}, j=1,2$, and eccentricity strictly less than unity. However, $T$ is a convexoid by hypothesis and Co $(\sigma(T))$ is a quadrilateral, a triangle or a line segment with all of its vertices lying on the two half-rays $e^{i \theta_{j}} \cdot \boldsymbol{R}^{+}, j=1,2$. Therefore, $A=0$ and $T=e^{i \theta_{1}} T_{1} \oplus e^{i \theta_{2}} T_{2}$.

The case that \#Arg $\sigma(T)=3$ is treated in a similar fashion. Nevertheless, we note that the above geometric argument fails if $\# \operatorname{Arg} \sigma(T) \geqq 4$. Fortunately this case cannot arise.

By the term polygon, we mean the rectilinear figure together with its interior domain; moreover, we do not exclude the degenerate cases of singletons and line segments. For $T \in \mathscr{B}(\mathscr{C})$, if $\bar{W}(T)$ is a polygon, then $T$ is convexoid [7, Satz 1]. Thus we have 
Corollary 1. Let $T \in \mathscr{B}(\mathscr{H})$. Suppose $0 \notin \bar{W}\left(T^{n}\right), n=1,2$, $3, \cdots$ Then $T$ is normal if and only if $\bar{W}(T)$ is a polygon.

We note that the polygon mentioned in Corollary 1 may have at most six sides.

4. Commutators. There are interesting applications of the above results to the theory of commutators. Let $\mathfrak{S}$ be a separable infinite dimensional Hilbert space, $\mathscr{K}(\mathfrak{S})$ the set of all compact operators on $\mathscr{S}$ and $\Pi$ the canonical homomorphism from $\mathscr{B}(\mathscr{S})$ onto the Calkin algebra, $\mathscr{B}(\mathfrak{S}) / \mathscr{K}(\mathfrak{S})$. There exists an isometric *-isomorphism $\tau$ of the Calkin algebra onto a closed self-adjoint subalgebra of $\mathscr{B}(\mathscr{H})$, where $\mathscr{H}$ is a suitably chosen Hilbert space [16, Theorem 12.41]. For $T \in \mathscr{B}(\mathfrak{S})$, the Weyl spectrum $\sigma_{W}(T)$ is the largest subset of $\sigma(T)$ which is invariant under compact perturbations, $\sigma_{W}(T)=\cap\{\sigma(T+K): K \in \mathscr{K}(\mathfrak{S})\}$. In [5] it is shown that $\sigma_{W}(T)$ consists of $\sigma(\tau(\Pi(T)))$ together with some of the bounded components of the complement of $\sigma(\tau(\Pi(T)))$. Consequently if $\sigma_{W}(T)$ lies on a simple arc, $\sigma_{W}(T)=\sigma(\tau(\Pi(T)))$.

Lemma 6 ([11], [4, p. 62]). Let $T \in \mathscr{B}(\mathfrak{S})$. Suppose $\tau(\Pi(T))$ is normal and $\sigma(\tau(\Pi(T)))$ lies on a simple arc. Then, there exists a compact operator $K$ such that $T+K$ is normal and $\sigma(T+K)=$ $\sigma(\tau(\Pi(T)))$.

The essential numerical range of $T \in \mathscr{B}(\mathfrak{S})$ is the set $W_{e}(T)=$ $\cap\{\bar{W}(T+K): K \in \mathscr{C}(\mathfrak{S})\}$. By [17, Theorem 9] and [2, Theorem 3], $W_{e}(T)=\bar{W}(\tau(\Pi(T)))$. Let $\mathscr{R}$ denote $\{S X-X S: S, X \in \mathscr{B}(\mathscr{S}), S>0\}$. In [1], J. H. Anderson proved the following deep result: $\mathscr{R}=\{T \in$ $\left.\mathscr{B}(\mathfrak{C}): 0 \in W_{e}(T)\right\}$; also see [3, $\left.\S 34\right]$. Corresponding to Theorem 1', we have

THEOREM 3. Let $T \in \mathscr{B}(\mathfrak{S})$. Suppose $T^{n} \notin \mathscr{R}, n=1,2,3, \cdots$. Then we have the following cases:

(i ) $\sharp \operatorname{Arg} \sigma_{W}(T)=1$, then there exist $\theta \in[0,2 \pi)$ and a compact operator $K$ such that $\left(e^{i \theta} T+K\right)>0$.

(ii) $\sharp \operatorname{Arg} \sigma_{W}(T) \geqq 3$, then $\sharp \operatorname{Arg} \sigma_{W}(T)=3$ and there exist $\theta \in[0,2 \pi)$ and a compact operator $K$ such that $\left(e^{i \theta} T^{7}+K\right)>0$.

(iii) $\# \operatorname{Arg} \sigma_{W}(T)=2$, then either there exist a positive odd integer $m, \theta \in[0,2 \pi)$ and a compact operator $K$ such that $\left(e^{i \theta} T^{m}+\right.$ $K)>0$, or there exist a closed subspace $\mathfrak{S}_{1}$ of $\mathfrak{S}$ and positive operators $T_{1}$ and $T_{2}$ on $\mathfrak{S}_{1}$ and $\mathfrak{S}_{1}^{\perp}$ respectively such that $\left(T-e^{i \theta_{1}} T_{1} \oplus e^{i \theta_{2}} T_{2}\right)$ is compact, where $\left(\theta_{1}-\theta_{2}\right)$ is a number irrational modulo $2 \pi$.

Proof. We only need to prove the second half of case (iii). 
We know $\tau(\Pi(T))=e^{i \theta_{1}} V_{1} \oplus e^{i \theta_{2}} V_{2}$ on $\mathscr{H}_{1} \oplus \mathscr{H}_{1}{ }^{1}=\mathscr{H}$, where $V_{1}>0$ and $V_{2}>0$. Thus $\tau(\Pi(T))$ is normal and $\sigma(\tau \circ \Pi(T))$ lies on a simple arc. By Lemma 6 , there is a compact operator $K$ such that $T+K$ is normal and $\sigma(T+K)=\sigma(\tau(\Pi(T)))$. Consequently, there exist a closed subspace $\mathscr{S}_{1}$ of $\mathscr{S}$ and positive operators $T_{1}$ and $T_{2}$ on $\mathfrak{F}_{1}$ and $\mathfrak{S}_{1}^{\perp}$ respectively such that $\left(T-e^{i \theta_{1}} T_{1} \oplus e^{i \theta_{2}} T_{2}\right)$ is compact.

TheOREM 4. Let $T \in \mathscr{B}(\mathfrak{Y})$. Suppose $T^{n} \notin \mathscr{R}, n=1,2,3, \cdots$. Then $T$ is a compact perturbation of a normal operator if and only if $W_{e}(T)$ is a polygon.

\section{Proof. Apply Corollary 1.}

\section{REFERENCES}

1. J. H. Anderson, Derivations, Commutators, and the Essential Numerical Range, Ph. D. Thesis, Indiana University (1971).

2. S. K. Berberian and G. H. Orland, On the closure of the numerical range of an operator, Proc. Amer. Math. Soc., 18 (1967), 499-503.

3. F. F. Bonsall and J. Duncan, Numerical Ranges II, Cambridge University Press, London (1973).

4. A. Brown, R. G. Douglas and P. A. Fillmore, Unitary equivalence modulo the compact operators and extensions of $C^{*}$-algebras, Proc. Conf. on Operator Theory, Lecture Notes in Math., Vol. 345, Springer-Verlag, New York (1973).

5. P. A. Fillmore, J. G. Stampfli and J. P. Williams, On the essential numerical range, the essential spectrum, and a problem of Halmos, Acta Sci. Math. (Szeged), 33 (1972), 179-192.

6. P. R. Halmos, A Hilbert Space Problem Book, Van Nostrand, Princeton, New Jersey (1967).

7. S. Hildebrandt, Über der numerischen Wertebereich eines Operators, Math. Ann., 163 (1966), 230-247.

8. C. R. Johnson, Powers of matrices with positive definite real part, Proc. Amer. Math. Soc., 50 (1975), 85-91.

9. C. R. Johnson and M. Newman, Triangles generated by powers of triplets on the unit circle, J. Research Nat. Bur. Standards Sec. B, 77B (1973), 137-141.

10. R. Kippenhahn, Über der Wertevorrat einer Matrix, Math. Nachr., 6 (1951), 193-228.

11. J. S. Lancaster, Lifting from the Calkin Algebra, Ph. D. Thesis, Indiana University (1972).

12. F. D. Murnaghan, On the field of a square matrix, Proc. Nat. Acad. Sci., U.S.A. 18 (1932), 246-248.

13. H. Radjavi and P. Rosenthal, Invariant Subspaces, Springer-Verlag, New York (1973).

14. E. S. W. Shiu, Numerical Ranges of Powers of Operators, Ph. D. Thesis, California Institute of Technology (1975).

15. - Growth of numerical ranges of powers of Hilbert space operators, Michigan Math. J., (in print).

16. W. Rudin, Functional Analysis, McGraw-Hill, New York (1973).

17. J. G. Stampfli and J. P. Williams, Growth conditions and the numerical range in a Banach algebra, Tôhoku Math. J., 20 (1968), 417-424.

18. A. E. Taylor, Introduction to Functional Analysis, Wiley, New York (1958). 
Received November 24, 1975 and in revised form March 30, 1976. This paper consists of a portion of the author's $\mathrm{Ph}$. $\mathrm{D}$. thesis under the supervision of Professor C. R. DePrima at the California Institute of Technology.

UNIVERSITY OF MANITOBA 



\section{PACIFIC JOURNAL OF MATHEMATICS}

\section{EDITORS}

RICHARD ARENS (Managing Editor)

University of California

Los Angeles, California 90024

\section{R. A. Beaumont}

University of Washington

Seattle, Washington 98105
J. DugundjI

Department of Mathematics

University of Southern California

Los Angeles, California 90007

D. Gilbarg and J. Milgram

Stanford University

Stanford, California 94305

\section{ASSOCIATE EDITORS}
E. F. BECKENBACH
B. H. NeumanN
F. WOLF
K. YosHIDA

\section{SUPPORTING INSTITUTIONS}

\author{
UNIVERSITY OF BRITISH COLUMBIA \\ CALIFORNIA INSTITUTE OF TECHNOLOGY \\ UNIVERSITY OF CALIFORNIA \\ MONTANA STATE UNIVERSITY \\ UNIVERSITY OF NEVADA \\ NEW MEXICO STATE UNIVERSITY \\ OREGON STATE UNIVERSITY \\ UNIVERSITY OF OREGON \\ OSAKA UNIVERSITY
}

\author{
UNIVERSITY OF SOUTHERN CALIFORNIA \\ STANFORD UNIVERSITY \\ UNIVERSITY OF HAWAII \\ UNIVERSITY OF TOKYO \\ UNIVERSITY OF UTAH \\ WASHINGTON STATE UNIVERSITY \\ UNIVERSITY OF WASHINGTON \\ AMERICAN MATHEMATICAL SOCIETY
}

The Supporting Institutions listed above contribute to the cost of publication of this Journal, but they are not owners or publishers and have no responsibility for its content or policies.

Mathematical papers intended for publication in the Pacific Journal of Mathematics should be in typed form or offset-reproduced, (not dittoed), double spaced with large margins. Please do not use built up fractions in the text of your manuscript. You may however, use them in the displayed equations. Underline Greek letters in red, German in green, and script in blue. The first paragraph or two must be capable of being used separately as a synopsis of the entire paper. Items of the bibliography should not be cited there unless absolutely necessary, in which case they must be identified by author and Journal, rather than by item number. Manuscripts, in triplicate, may be sent to any one of the editors. Please classify according to the scheme of Math. Reviews, Index to Vol. 39. All other communications should be addressed to the managing editor, or Elaine Barth, University of California, Los Angeles, California, 90024.

The Pacific Journal of Mathematics expects the author's institution to pay page charges, and reserves the right to delay publication for nonpayment of charges in case of financial emergency.

100 reprints are provided free for each article, only if page charges have been substantially paid. Additional copies may be obtained at cost in multiples of 50 .

The Pacific Journal of Mathematics is issued monthly as of January 1966. Regular subscription rate: $\$ 72.00$ a year (6 Vols., 12 issues). Special rate: $\$ 36.00$ a year to individual members of supporting institutions.

Subscriptions, orders for back numbers, and changes of address should be sent to Pacific Journal of Mathematics, 103 Highland Boulevard, Berkeley, California, 94708.

PUBLISHED BY PACIFIC JOURNAL OF MATHEMATICS, A NON-PROFIT CORPORATION

Printed at Kokusai Bunken Insatsusha (International Academic Printing Co., Ltd.), 8-8, 3-chome, Takadanobaba, Shinjuku-ku, Tokyo 160, Japan. 


\section{Pacific Journal of Mathematics \\ Vol. 65, No. $2 \quad$ October, 1976}

Andrew Adler, Weak homomorphisms and invariants: an example .......... 293

Howard Anton and William J. Pervin, Separation axioms and metric-like

functions ............................................. 299

Ron C. Blei, Sidon partitions and p-Sidon sets .................... 307

T. J. Cheatham and J. R. Smith, Regular and semisimple modules ........... 315

Charles Edward Cleaver, Packing spheres in Orlicz spaces .............. 325

Le Baron O. Ferguson and Michael D. Rusk, Korovkin sets for an operator on a

space of continuous functions ............................. 337

Rudolf Fritsch, An approximation theorem for maps into Kan fibrations ....... 347

David Sexton Gilliam, Geometry and the Radon-Nikodym theorem in strict

Mackey convergence spaces .................................

William Hery, Maximal ideals in algebras of topological algebra valued

functions ...................................... 365

Alan Hopenwasser, The radical of a reflexive operator algebra ........... 375

Bruno Kramm, A characterization of Riemann algebras................. 393

Peter K. F. Kuhfittig, Fixed points of locally contractive and nonexpansive

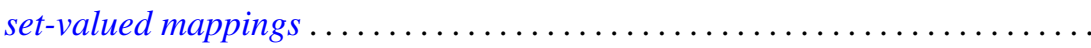

Stephen Allan McGrath, On almost everywhere convergence of Abel means of

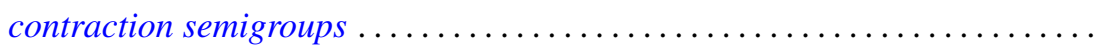

Edward Peter Merkes and Marion Wetzel, A geometric characterization of

indeterminate moment sequences............................ 409

John C. Morgan, II, The absolute Baire property ................... 421

Eli Aaron Passow and John A. Roulier, Negative theorems on generalized convex approximation .................................... 437

Louis Jackson Ratliff, Jr., A theorem on prime divisors of zero and characterizations of unmixed local domains ..............

Ellen Elizabeth Reed, A class of $T_{1}$-compactifications................... 471

Maxwell Alexander Rosenlicht, On Liouville's theory of elementary

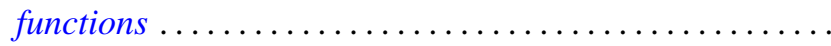

Arthur Argyle Sagle, Power-associative algebras and Riemannian

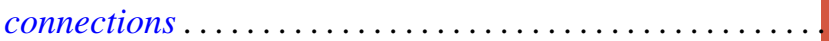

Chester Cornelius Seabury, On extending regular holomorphic maps from Stein manifolds...

Elias Sai Wan Shiu, Commutators and numerical ranges of powers of operators ...................................

Donald Mark Topkis, The structure of sublattices of the product of $n$ lattices ... 525

John Bason Wagoner, Delooping the continuous $K$-theory of a valuation

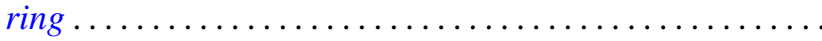

Ronson Joseph Warne, Standard regular semigroups...........

Anthony William Wickstead, The centraliser of $E \otimes_{\lambda} F \ldots$. 